\title{
ATIVIDADES LÚDICAS PARA ALUNOS COM DIFICULDADES NA ALFABETIZAÇÃO
}

Bianca Alves ${ }^{1}$; Sávio Araújo do Prado ${ }^{2}$; Luciana Custódio da Silva ${ }^{3}$; Paulo Alexandre de Castro $^{4}$; Leonardo santos Andrade ${ }^{5}$; Adriana S.P. Sadoyama ${ }^{6}$; Geraldo Sadoyama Leal ${ }^{7}$

\section{Resumo}

Cada aluno tem uma forma diferente de absorver e aprender o que o professor passa em sala de aula. Em alguns casos, o aluno apresenta dificuldades de aprendizagem com o modo didático escolhido pelo professor. O objetivo deste trabalho foi fazer com que, houvesse um aumento no desempenho dos alunos selecionados. Estes foram, quatro alunos da Escola Municipal Nilda Margon Vaz do $3^{\circ}$ ano do ensino fundamental I, que apresentam desempenho acadêmico menor. Os pibidianos se propuseram à elaborar atividades de ensino lúdicas para ministrar o conteúdo aos alunos. Foram utilizados jogos de memória, com imagens, onde ao acertar o par de imagens, os alunos teriam que identificar e transcrever o objeto visualizado. Jogos de mímica foram feitos pelos próprios alunos, que quando os demais descobriam o que estava sendo imitado, descreviam. Os alunos obtiveram resultados positivos, onde os próprios deixaram clara a gratidão da aula e o cuidado dos pibidianos, questionando inclusive sobre quando haverão outras aulas, pois, a dificuldade que sentiam foi claramente reduzida, fazendo assim, com que os alunos se sentissem mais a vontade dentro de sala de aula com seus colegas que não apresentam as mesmas dificuldades. Houve melhoria no desempenho da interpretação, na participação de atividades, onde houve uma maior participação

\section{Discente do PIBID Interdisciplinar/Regional Catalão/UFG. E-mail: bianca.alves96@hotmail.com}

2 Discente do PIBID Interdisciplinar/Regional Catalão/UFG. E-mail: savsou@gmail.com

3 Professor Supervisor do PIBID Interdisciplinar/Regional Catalão/FG. E-mail: lanacustodio@ hotmail.com

${ }^{4}$ Coordenador de Área do Subprojeto Interdisciplinar - (PIBID, UFG/RC), E-mail: padecastro@ufg.br

5 Coordenador de Área do Subprojeto Interdisciplinar - (PIBID, UFG/RC), E-mail: 1s_andrade@yahoo.com.br

${ }^{6}$ Coordenadora de Área do Subprojeto Interdisciplinar - (PIBID, UFG/RC), E-mail: drisadoyama@gmail.com

7 Coordenador de Área do Subprojeto Interdisciplinar - (PIBID, UFG/RC), E-mail: gsadoyama@yahoo.com.br 
feminina. Foi observado que entre os alunos havia uma variação no nível de entendimento e escrita, visto que, detectou-se quatro alunos com dificuldade de escrita. Essa variação dos estímulos para o aprendizado é de suma importância, pois, a quebra de rotina da sala de aula gera um melhor dinamismo entre os alunos, gerando assim, melhores resultados na aprendizagem.

Apoio: PIBID/CAPES

Palavras Chave: jogos, alfabetização. 